\title{
Angiodysplasia of the Colon and Rectum. Case Report
}

\author{
Sierra Montenegro Ernesto ${ }^{1 *}$, Sierra Luzuriaga Gaston ${ }^{2}$, Cruz Lavayen Victor ${ }^{3}$, Zambrano \\ Abad Fabian ${ }^{4}$, Merchan Camacho Eduardo ${ }^{5}$, Solis Salazar Ivan ${ }^{6}$ \\ ${ }^{1}$ Head, Coloproctology Unit, Teodoro Maldonado Carbo Hospital Guayaquil-Ecuador, Inpatient Director, \\ Coloproctology Postgrad Program, UESS \\ ${ }^{2}$ Director, Coloproctology Postgrad Program, Espiritu Santo University, Guayaquil-Ecuador \\ ${ }^{3}$ Attending Physician, Coloproctology Unit \\ ${ }^{4}$ First Year Resident, Coloproctology Postgrad Program, UEES
}

\begin{abstract}
*Corresponding Author: Sierra Montenegro Ernesto, Head, Coloproctology Unit, Teodoro Maldonado Carbo Hospital Guayaquil-Ecuador, Inpatient Director, Coloproctology Postgrad Program, UESS, Ecuador, Email: gesierra21@yahoo.com
\end{abstract}

\begin{abstract}
In 1974 was the first time that to describe abnormal distributions of the vessels of the submucosa of the colon, used the term Angyodispla. The aim of this paper is to report a case of simultaneous angiodysplasia of the colon and rectum. Case report.- Male, 25 years old with a history of appendectomy at age 19 with massive bleeding during surgery. He came to the Hospital for presenting abundant bleeding, colonoscopy was done, finding the right colon to the liver flexure and in the rectum vessels engorgement at the submucosa, the other imaging studies was normal, we proposed surgery, he accepted. We done right colectomy with ileotransverso and colostomy. The pathology report was Angiodysplasia Colon and Rectum. There was successful evolution, but we performed colonoscopy by colostomy because he reported bleeding throw it, finding engorgement vessels at the submucosa of the remaining colon, we discussed the case on staff and decided to do total colectomy and ending ileostomyl and in the future pouch ileoanal, the patient did not accept. Discussion.- Vascular lesions can be associate with some syndroms in this patient were discarded, performing hepatic, and renal studies, the presentation of these pathologies is after 60 years and surgery remains the treatment of choice. Conclusions.- In young patients with gastrointestinal bleeding an colonoscopy will be performed if the basic studies do not show organic pathology.
\end{abstract}

Keywords: angiodysplasia, bleeding

\section{INTRODUCTION}

The first case of angiodysplasia (AD) reported in the literature was described in 1839 , but it was not until 1974 that the term $\mathrm{AD}$ was used to describe abnormal distributions in the submucosal vessels of the colon1.

$\mathrm{AD}$ may be defined as the finding of abnormal, ectatic, dilated, winding and usually small $(<10$ $\mathrm{mm}$ ) blood vessels. Histologically, the vessels involved are exclusively limited to the endothelium with little or no presence of connective tissue2. Several publications suggest that the colon is one of the most frequent sites for the occurrence of $\mathrm{AD} 3,4$, and angiodysplasia of the colon was reported for the first time as a hemangioma of the sigmoid colon by Holman5, and Marguillis6, et al.

The purpose of this case is to report a patient who presented angiodysplasia of the colon and rectum simultaneously.

\section{CASE REPORT}

This is a 25- year- old male with a history of appendectomy at 19 years of age who, according to a relative, had massive hemorrhaging during post-op, at the drainage site left after surgery, and had to receive several transfusions. He later presented sporadic abundant rectorrhagia, twice, before he was seen by Coloproctology at the Teodoro Maldonado Carbo Hospital in Guayaquil, Ecuador. He was therefore referred to our unit. We performed a colonoscopy and found engorged vessels from the cecum up to the hepatic flexure in the right colon (Fig. 1) with the same finding in the rectum (fig. 2); the rest of the scan was normal. We ran tests to rule out liver pathology, with negative results and performed an angiotomography with normal results. We proposed surgery, which was accepted. We performed a right hemicolectomy during the surgical act, with terminal-lateral 
ileoanastomosis. We then dissected the rectum but observed, apart from a narrow pelvis, engorgement of the vessels of the middle rectal artery, and therefore decided to perform Hartmann's procedure. Pathology reported macroscopy of 2 segments of intestine and several fragments of epiploon. The largest segment measured $24 \mathrm{~cm}$ in length with a diameter between 3 and $4 \mathrm{~cm}$ and showed congested meso-colon and brownish frosted serosa. When cut, there was a cystic area measuring $3 \times 2 \mathrm{~cm}$. the mucosal folds were preserved with brownish and hemorrhagic areas; the cystic area was $10 \mathrm{~cm}$ from the proximal margin and $12 \mathrm{~cm}$ from the distal margin. When cut, the wall showed several thrombi, the mesocolon had a nodular, rounded area measuring $4 \mathrm{x}$ $3 \times 3 \mathrm{~cm}$. The smallest measured $12 \mathrm{~cm}$ in length with a diameter between 2 and $3 \mathrm{~cm}$, with purplish areas. When cut it showed invaginations of the mucosa which contained several fecaliths which reached the meso-colon. Microscopy reported a thin intestinal wall with edema and proliferation of congestive vascular structures, and thrombi in the lumen, along the entire wall up to the meso-colon. The rectal wall showed thinning of the muscular layer, edema, focal lymphoplasmacytic inflammatory infiltrate, proliferation of vascular structures and thrombi in the lumen, consistent with Angiodysplasia of the Colon and Rectum. Progress was satisfactory and, 8 months after surgery, when he was being scheduled for intestinal transit restitution, he stated that he had presented with hemorrhaging due to the colostomy. We therefore decided to perform a colonoscopy through the stoma, again finding engorgement of the entire remaining colon, up to $15 \mathrm{~cm}$ from the colostomy margin, and requested an angio-CT with normal findings. We discussed the case during the unit staff meeting and decided to perform a total colectomy and terminal ileostomy and, in the future, an ileoanal reservoir, which the patient did not accept.

\section{Discussion}

Aberrant blood vessels are most frequently found in the gastrointestinal tract where they are considered to be more common than at other sites. The reason for the changes in the observed vascular structures with increase in age is poorly understood 7,8 .

The terms "angiodysplasia", "arteriovenous malformation", "angioectasia" and "vascular ectasia" are synonymous. Angiodysplasias are differentiated from telangiectasias, which are similar but generally associated with congenital diseases. Additionally, some authors use the term "angioectasia" as a generic term, leaving "angiodysplasia" for lesions of the colon.9

Vascular abnormalities can be divided into three large groups: a) vascular tumors or angiomas which may be benign (hemangiomas) or malignant (angiosarcomas); b) vascular abnormalities associated with congenital or systemic diseases, such as Klippel-Trenaunay Weber, Ehlers-Danlos, CREST and OslerWeber-Rendu syndromes; and c) acquired abnormalities or sporadic lesions such as angiodysplasias9.

Most ADs are detected in patients older than 60 years 10, although it has been reported in 30year-old patients 11 . In our case, the interesting part is that the patient had it at age 19, when he had surgery for his appendix, and was then seen by us at 24 .

Generally, patients are mostly asymptomatic and $\mathrm{AD}$ can be found in routine exams or with a history of chronic lower gastrointestinal bleeding. Their distribution is as follows: cecum $37 \%$, ascending colon $17 \%$, transverse colon $7 \%$, descending colon $7 \%$, sigmoid colon $18 \%$, and rectum $14 \%$. Western patients show involvement of the right colon (54 - 81.9\%)12, while the Japanese most frequently present involvement of the descending colon $(41.7 \%) 3$, 8. In our case, simultaneous presence in the right colon and rectum is remarkable, and it has not been reported in the literature.

The pathogenesis of colonic angioectasia may be the result of a chronic, partial, intermittent, low-grade obstruction of the submucosal veins, where they penetrate the muscular layer of the colon, and by mechanical compression may be induced to the tension of the colon 4 - 13 . Laplace's law explains this theory better, to evaluate wall tension, where tension is high when the radius is increased and wall thickness is decreased. This applies to the ascending colon and cecum (large diameter with thin wall) 14 .

Diagnosis is made with colonoscopy, where angiodysplasia appears as a red, flat and shiny area with regular edges, like a "coral bank".15. This was not noticeable in these images, in the case of the patient we present, however of submucosal vein engorgement at the previously mentioned sites was seen.

Differential diagnosis of $\mathrm{AD}$ established as the cause of the Lower Digestive Hemorrhaging, 
must be associated with certain risk factors or associated conditions. Thus, the association of aortic stenosis and gastrointestinal hemorrhaging described by Heyde16 in 1958, which was is named after him. Likewise, type-2 acquired Von Willebrand syndrome, which is been reported to represent $67-92 \%$ of patients with severe aortic stenosis who require valve replacement17, 18, and finally, it is associated with patients with chronic kidney failure, because, because causes an alteration in the previously explained mechanism of pathogenesis due, to its chronicity 19. We requested the corresponding tests and there was no evidence of cardiac, kidney or liver involvement, or hematological disorders.

Management of patients with $\mathrm{AD}$, in terms of endoscopic therapies, includes Argon Plasma Coagulation (APC), the most widely used method for treatment of AD20. Electrocoagulation, which was used in the early $80 \mathrm{~s}$, is not currently recommended due to the high risk of severe complications, one of them perforation in $9 \%$ of cases 21 . Photocoagulation using Nd:YAG has been reported in some studies22; the use of endo clips has shown safety and effectiveness in the few cases reported using endoscopic clipping for $\mathrm{AD} 23$, and other studies that are used more for management of gastrointestinal hemorrhaging than for $\mathrm{AD}$ as such. Our case did not warrant any of these endoscopic possibilities.

Surgery is the definitive treatment for clearly identified lesions, aimed at patients with severe gastrointestinal hemorrhaging which cannot be controlled by any of the other therapies described above, or for patients with recurring chronic hemorrhaging, or dependent on blood transfusions24. We decided that our initial option was surgery after identifying the site of the lesion with no other concomitant disease, because we had a young, stable patient, and we expected good results for a very delicate pathology, with previous pathology report of angiodysplasia.

Hormone therapy has also been described for treatment of $\mathrm{AD}$, such as the use of thalidomide which is an angiogenesis inhibitor that suppresses the vascular endothelial growth factor. Good results have been obtained in some series, but with a high number of adverse events, such as fatigue (32\%), constipation (25\%), dizziness (21\%), and peripheral edema (14\%), and less frequently, abdominal distention, thrombocytopenia, leukopenia, blurry vision, dry eyes, pruritus, rash, headache and herpes zoster 25 .

\section{CONClusion}

The patient with $\mathrm{AD}$ has been admitted to an emergency center on several occasions after presenting with Gastrointestinal Hemorrhaging. Once we have diagnosed him, we must effectively administer the treatment we will offer him to increase his quality of love. Unfortunately, in our case, an endoscopic review and post-surgical follow-up showed that the patient presented with engorgement of previously healthy tissue at the level of the submucosa of the colon and he did not accept surgical treatment. We believe that a genetic study would be ideal to obtain any additional malformation but, unfortunately, we do not have this procedure.

\section{REFERENCES}

[1] Athanasoullis CA, Galdabini JJ, Waltman AC, Novelline RA, Greenfield AJ, Ezpeleta MI. Angiodysplasia of the colon a cause of rectal bleeding. Cardiosvac Radiol 1977;1 : 3- 13.

[2] Poralla T. Angiodysplasia in the renal patient: how to diagnose and how to treat? Nephrol Dial Transplant 1998; 13: 2188-93

[3] Ueno S, Nakase H, Kisahara K, et al. Clinical features of Japanese patients with colonic angiodysplasia, J Gastroenterol Hepatol, 2008; 8: 363-6.

[4] Muñoz-Navas M, Ibañez MB, Sainz IF, Chronic gastroinestinal bleeding, Clinical Gastrointestinal endoscopy. 2005; 213-37.

[5] Holman CC. Hemangioma of the sigmoid colon. Br J Surg 1948; 36: 210.

[6] Marguilis AR, Heinbecker P, Bernard HR. Operative mesenteric arteriography in the search for the site of bleeding in unexplained gastrointestinal hemorrhage. Surgery 1960; 48: 534-9.

[7] Moore JD, Thompson NW, Appelman HD, Foley D. Arteriovenous malformations of the gastrointestinal tract. Arch Surg 1976; 111: 381.

[8] Duray PH, Marcal JM Jr, Li Volsi VA, et al. Small intestinal angiodysplasia in the elderly. J Clin Gastroenterol 1984; 6: 311.

[9] Schmit A, Van Gossum A. Proposal for endoscopic classiffication of digestive angiodysplasia for therapeutic trials. The European Club of Enteroscopy Gastrointesti Endosc 1998; 48: 659.

[10] Foutch, PG, Rex DK, Lieberman DA. Prevalence and natural history of colonic angiodysplasia among healthy asymptomatic people. Am J Gastroenterol 1995; 90: 564-7. 
[11] Jesudason SR, Devasia A, Mathen VI, et al. The pattern of angiodysplasia of the gastrointestinal tract in tropical country. Surg Gynecol Obstet 1985; 161: 525.

[12] Höchter W, Weingart J, Kühner W, et al. Angiodysplasia in the colon and rectum, Endoscopic morphology, lacalization and frequency. Endoscopy 1985; 17: 182.

[13] Boley ST, Sammartano R, Adams A, et al. On the nature and etiology of vascular ectasias of the colon degenerative lesions of aging. Gastroenterology 1977; 72: 650-660.

[14] James MA, Saadeh AM, Jones JV. Wall stress and hypertension. J Cardiovasc Risk 2000; 7: 187-90.

[15] Fouch PG. Colonic angiodysplasia. Gastroenterologist 1997; 5: 148-156.

[16] Heyde EC. Gastrointestinal bleeding in aortic stenosis N Engl J Med 1958; 259: 196.

[17] Gostour CT. Angiodysplasia and aortic valve disease: let's closet he book on this association. Gastrointes Endoscp 1995; 42: 491-3.

[18] Vincentelli A, Susen S, Le Tourneau T, et al. Acquired von Willebrand síndrome in aortic stenosis. N Engl J Med 2003; 4: 343-9.

[19] Chalasani N, Cotsonis G, Wilcox CM. Upper gastrointestinal bleeding in patients con chronic renal failure role of vascular ectasia. Am J Gastroenterol 1996; 91: 2329-32

[20] Virgo JJ. Clinical applications of the argón plasma coagulator. Gastrointest Endosc 2004; 59: $81-8$

[21] Richter JM, Christensen MR, Colditz GA, Nishioka NS. Angiodysplasia Natural history and efficacy of therapeutic interventions. Dig Dis Sci 1989; 34: 1542-6

[22] Selinger RR, Mc Donald GB, Hockenbery DM, Steinbach G, Kimmey MB. Efficacy of neodymiun YAG laser therapy for gastric antral ectasia (GAVE) following hematopoietic cell transplant. Bone Marrow transplant 2006; 37 : 191-7.

[23] Takahashi N, Tanabe K, Yoshitomi H, et al. Successful endoscopic clipping for bleeding from colonic angiodysplasia in a case of Heyde síndrome. Med Sci Monitt 2010; 16: CS107-9.

[24] Czymer R, Kempf A, Roblick UJ, et al. Surgical treatment concepts for acute lower gastrointestinal bleeding. J Gastroenterol Surgery 2008; 12: 2212-20.

[25] Chen HM, Ge ZZ, Liu WZ, et al. The mechanism of thalidomide in treatment of angiodysplasia due to hipoxia. Zronghua Net Ke Za Zri 2009; 48: 295-8.

Citation: Sierra Montenegro Ernesto et al., Angiodysplasia of the Colon and Rectum. Case Report. ARC Journal of Clinical Case Reports. 2017; 3(3):1-4. doi:dx.doi.org/10.20431 /2455-9806.0303001.

Copyright: (C) 2017 Authors. This is an open-access article distributed under the terms of the Creative Commons Attribution License, which permits unrestricted use, distribution, and reproduction in any medium, provided the original author and source are credited. 